\title{
Impact of functional severity on self concept in young people with spina bifida
}

\author{
P E Minchom, N C Ellis, P L Appleton, V Lawson, V Böll, P Jones, C E Elliott
}

Department of Paediatrics, Wrexham Maelor Hospital P E Minchom $\checkmark$ Lawson

School of Psychology, University of Wales, Bangor

N C Ellis

Clwydian Community Care NHS Trust P L Appleton

C E Elliott

Child Health and Disability Service, Clwyd Social Services V Böll

P Jones

Correspondence to: Dr P E Minchom

Department of Paediatrics, Department of Paediatrics, Wrexham Maelor Wrexham, Clwyd LL13 7TD.

Accepted 10 March 1995

Table 1 Numbers of spina bifida subjects by age

\begin{tabular}{cr}
\hline Age (years) & No \\
\hline $7 \cdot 0-7 \cdot 9$ & 3 \\
$8 \cdot 0-8 \cdot 9$ & 3 \\
$9 \cdot 0-9 \cdot 9$ & 3 \\
$10 \cdot 0-10 \cdot 9$ & 10 \\
$11 \cdot 0-11 \cdot 9$ & 9 \\
$12 \cdot 0-12 \cdot 9$ & 9 \\
$13 \cdot 0-13 \cdot 9$ & 8 \\
$14 \cdot 0-14 \cdot 9$ & 6 \\
$15 \cdot 0-15 \cdot 9$ & 6 \\
$16 \cdot 0-16.9$ & 4 \\
$17 \cdot 0-17.9$ & 11 \\
$18 \cdot 0-18.9$ & 7
\end{tabular}

\begin{abstract}
This study examines the relationship between medical and functional severity of disability and levels of self esteem and self concept in 79 young people with spina bifida. Greater feelings of global self worth and of self esteem in physical appearance were associated with greater severity of disability. This was only in part an effect of lower IQ among the most disabled young people. Many of the least disabled had marked impairment of self esteem. Analysis of the impact of individual aspects of disability confirmed the association between increased self esteem in physical appearance and global self worth, and diminished functional ability. Academic self ratings, however, were higher in the less disabled. Hydrocephalus and continence appeared to have minimal effect on self esteem.
\end{abstract}

The relationship between severity of disability in spina bifida and self concept is complex and mediated by a range of factors. It is incorrect to assume that the psychological impact is less in the mildly disabled young person.

(Arch Dis Child 1995; 73: 48-52)

Keywords: spina bifida, severity of disability, self concept.

The perceptions, self esteem, and relative values of young people with physical disability are difficult to assess. Some studies suggest they have low levels of self esteem while others fail to demonstrate any differences between the physically disabled and controls. ${ }^{12}$

Spina bifida presents a complex pattern of disability with a variable impact on mobility, continence, and intelligence. Previous studies have shown little or no difference from controls in measures of self esteem ${ }^{4}$ or psychosocial adjustment. ${ }^{5}$ We have reported evidence of specific areas of diminished self esteem. ${ }^{6}$

Although the correlation between medical aspects of physical disability and functional impairment is well recognised, the relative psychological impact associated with different levels of severity is unclear. Two studies of spina bifida found no association between severity and psychosocial adjustment. ${ }^{78}$ In rheumatoid arthritis, research appears to indicate a diminution in psychosocial adjustment in those with milder disability. ${ }^{9}$

We carried out a multidisciplinary study of the self image of children and adolescents with spina bifida, including medical and psychological assessment. This paper assesses the impact of severity of disability on self esteem.

\section{Methods}

STUDY POPULATION

The study group, aged $7 \cdot 0$ to 18.9 years (table 1), had spina bifida, with or without hydrocephalus. There was a measurable impairment of sensation, motor skills, continence, or intellect in all cases. Of 104 families approached, $17(16 \%)$ refused and eight children were excluded on grounds of severely limited intellect or because of major current family stresses. The ascertainment method and description of the study group has been fully reported. ${ }^{6}$

\section{MEDICAL ASSESSMENT}

Medical assessment was carried out in 70 cases. Of the remainder, six refused and three were omitted for administrative reasons. Where clinical assessment was not possible information on history, physical findings, and function was acquired from medical notes. Details relating to mobility, continence, and independent function were recorded.

When a full clinical assessment was carried out the Pultibeced assessment of disability was completed. This comprises 12 items covering details of physical ability, independent function, communication, and intellect and has been used in both children and adolescents. ${ }^{1011} \mathrm{It}$ is not specific to spina bifida but defines functional disability.

In all cases, except for those with cervical lesions for whom it is not valid, a disability severity score as described by Wallander et al was completed. This measure was devised and standardised on children and young people. ${ }^{5}$ It is specific to spina bifida, defining severity on medical and functional parameters.

\section{ASSESSMENT OF SELF CONCEPT}

Self concept may be assessed in distinct academic, physical, and social domains. The Harter self perception profile for learning disabled students is designed to delineate this structure. The measure has been validated in children and young people with and without specific learning difficulties. ${ }^{12}$ The young people are asked to rate themselves in domains of self concept, including general intellect, academic skills, social acceptance, athletic competence, behavioural conduct, physical appearance, and global self worth (overall self esteem). Of the domains, that of physical appearance has been shown to be most closely correlated with global self worth. ${ }^{6} 13$ They are 

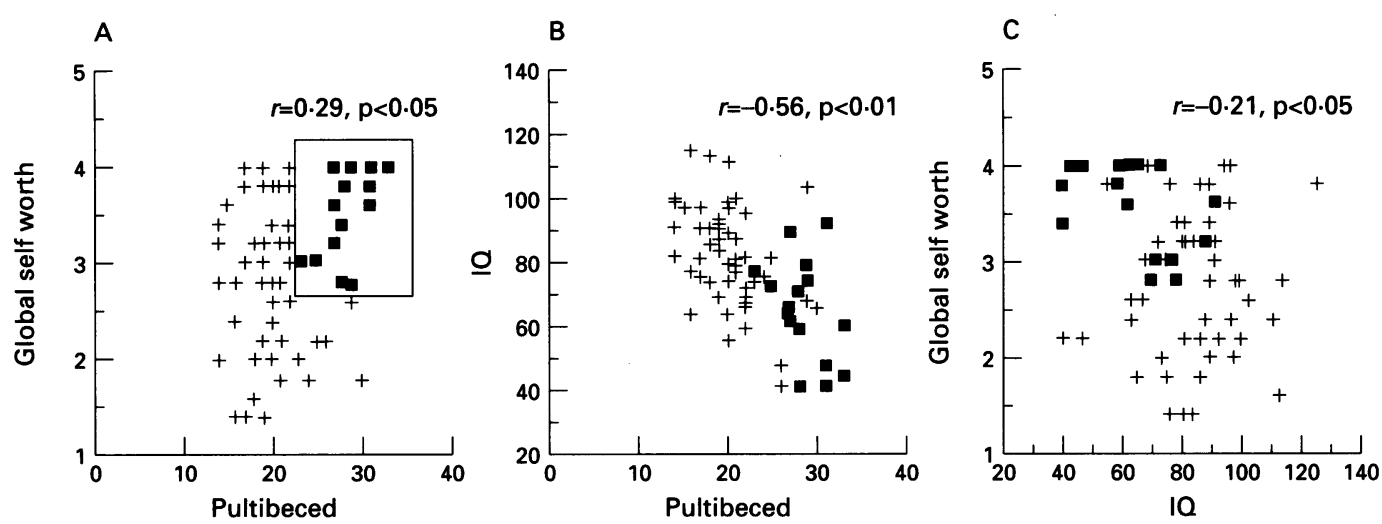

(A) Global self worth as a function of severity; (B) IQ as a function of severity; and (C) global self worth as a function of IQ: $\mathrm{a}=$ individuals $(n=16)$ with high severity and high global self worth (in $(A)$ two points overlap).

then asked to rate the importance of each domain to themselves. The difference between the importance ascribed to a domain and one's self rated competence in it is then calculated as a discrepancy score. It is calculated only for those domains rated highly in importance. Where there is a discrepancy between self rated competence and personal aspiration, self worth is also diminished. In order to protect self worth Harter postulated that individuals would diminish or 'discount' the importance of self concept domains to themselves. Appleton et al found no evidence of discounting in this spina bifida group. ${ }^{6}$

Psychological assessment included the Wechsler intelligence scale for children-revised or the Wechsler adult intelligence scale-revised as appropriate. ${ }^{14} 15$

\section{STATISTICS}

Test and questionnaire data were field coded by trained interviewers. All statistical analyses were performed using SPSS-X.

\section{Results}

STUDY SAMPLE CHARACTERISTICS

Complete details of the disabilities as defined by the Pultibeced and disability severity scores have been published. ${ }^{6}$

There were 79 patients in the study (38 male, 41 female). Three had cervical lesions, 33 thoracic, 32 lumbar, and 11 sacral. Seventy were evaluated clinically ( 34 male, 36 female) of whom three had cervical, 30 thoracic, 26 lumbar, and 11 sacral lesions. Hydrocephalus was present in 56 cases. Intraventricular valves were present in 52 . Three with hydrocephalus had no valve and one had a valve inserted and subsequently removed.

The mean IQ in the spina bifida group was 78.9 compared with 100.8 in an able bodied control group $(p<0 \cdot 0001)$. IQ was significantly lower in those with hydrocephalus $(75 \cdot 8)$ than without $(90.3)(p<0 \cdot 01){ }^{6}$

\section{GENDER AND SEVERITY}

There was no significant difference between the sexes in the measures of severity of disability.

\section{RELATIONSHIP OF SEVERITY OF DISABILITY TO} PSYCHOLOGICAL FINDINGS

When severity, defined by Pultibeced, is plotted against global self worth (fig A) there is a wide scatter and this is also evident when severity is assessed by disability severity score. However, there is a significant correlation with increased severity being associated with increased global self worth $(r=0.29, \mathrm{p}<0.05)$. This is also true for severity measured by the disability severity score $(r=0 \cdot 23, \mathrm{p}<0.05)$.

It was postulated that this effect may be related to a limitation in IQ in those most severely affected individuals with high global self worth (highlighted on the figures). Not unexpectedly IQ is inversely related to severity (fig B) and the severely affected individuals highlighted in fig A have the lowest IQs. When global self worth is plotted against IQ (fig C) it is evident that decreased IQ is associated with high levels of global self worth $(r=-0 \cdot 21, p<0 \cdot 05)$.

It is clear that severity of disability and associated lowering of cognitive function are interacting in affecting global self worth. In order to determine their independent effects subsequent analyses investigate: (1) which aspects of self concept are most affected by severity of disability, both as a general association and also disentangled from the confounding effect of IQ; (2) which aspects of physical disability most affect global self worth; and (3) the general associations of IQ and global self worth in this population and the specific effects of IQ on global self worth controlling for degree of physical disability.

EFFECTS OF SEVERITY AND IQ ON GLOBAL SELF WORTH AND DOMAINS OF SELF ESTEEM

To investigate the impact of severity and IQ on self esteem, the psychological parameters were assessed for their correlation with severity measures and reassessed when controlled for IQ (table 2). For the purposes of this analysis the academic domains were pooled to create a composite score of general academic ability.

Higher global self worth ratings were associated with higher severity as defined by either severity measure. When controlled for IQ, the Pultibeced association diminished but remained significant. The greater the severity by either measure the greater the physical 
Table 2 Correlations of competence and importance ratings and of discrepancy scores with measures of severity of disability and correlations controlled for $I Q$

\begin{tabular}{|c|c|c|c|c|}
\hline \multirow[b]{2}{*}{ Domain } & \multicolumn{2}{|c|}{ Raw correlation coefficients } & \multicolumn{2}{|c|}{ Correlations controlling for $I Q$} \\
\hline & $\begin{array}{l}\text { Pultibeced } \\
(n=70)\end{array}$ & $\begin{array}{l}\text { Disability } \\
\text { severity score } \\
(n=76)\end{array}$ & $\begin{array}{l}\text { Pultibeced } \\
\text { (n) }\end{array}$ & $\begin{array}{l}\text { Disability } \\
\text { severity score } \\
\text { (n) }\end{array}$ \\
\hline Global self worth & $0 \cdot 29^{\star}$ & $0 \cdot 23^{\star}$ & $0 \cdot 22(67)^{\star}$ & $0 \cdot 18(72)$ \\
\hline \multicolumn{5}{|l|}{ Competence: } \\
\hline General intellectual ability & 0.05 & -0.00 & $0 \cdot 19(67)$ & $0.07(72)$ \\
\hline General academic ability & $-0 \cdot 23$ & $-0 \cdot 22$ & $-0.02(67)$ & $-0.11(72)$ \\
\hline Social acceptance & -0.05 & -0.02 & $0.00(67)$ & $0.01(72)$ \\
\hline Athletics & $0 \cdot 11$ & $0 \cdot 16$ & $0 \cdot 16(67)$ & $0 \cdot 18(72)$ \\
\hline Behaviour & $0 \cdot 15$ & 0.11 & $0.07(67)$ & $0.05(72)$ \\
\hline Physical appearance & $0 \cdot 44^{\star \star}$ & $0 \cdot 26^{\star}$ & $0.36(67)^{\star \star}$ & $0 \cdot 20(72)^{\star}$ \\
\hline \multicolumn{5}{|l|}{ Importance: } \\
\hline General intellectual ability & -0.02 & 0.03 & $-0.01(62)$ & $0.04(67)$ \\
\hline General academic ability & 0.01 & 0.03 & $-0.05(63)$ & $0.01(68)$ \\
\hline Social acceptance & 0.09 & $0 \cdot 24^{\star}$ & $0 \cdot 16(62)$ & $0 \cdot 27(67)^{\star}$ \\
\hline Athletics & $0 \cdot 15$ & 0.02 & $0.20(62)$ & $0.03(67)$ \\
\hline Behaviour & 0.07 & $0 \cdot 15$ & $0.07(62)$ & $0 \cdot 15(67)$ \\
\hline Physical appearance & -0.09 & $0 \cdot 11$ & $-0.13(63)$ & $0 \cdot 11(68)$ \\
\hline \multicolumn{5}{|l|}{ Discrepancy: } \\
\hline General intellectual ability & $-0 \cdot 14$ & $-0 \cdot 22$ & $0.09(40)$ & $-0.11(43)$ \\
\hline General academic ability & $-0 \cdot 36^{\star \star}$ & $-0 \cdot 32^{\star}$ & $-0 \cdot 10(56)$ & $-0.08(61)$ \\
\hline Social acceptance & $-0 \cdot 12$ & -0.02 & $-0.07(38)$ & $0.02(41)$ \\
\hline Athletics & -0.02 & $-0 \cdot 14$ & $0.08(20)$ & $-0.10(72)$ \\
\hline Behaviour & -0.03 & -0.02 & $-0.07(54)$ & $-0.04(57)$ \\
\hline Physical appearance & $0 \cdot 40^{\star \star}$ & $0 \cdot 12$ & $0 \cdot 22(44)$ & $-0.02(47)$ \\
\hline
\end{tabular}

Significance: ${ }^{\star} \mathrm{p}<0 \cdot 05 ;{ }^{\star \star} \mathrm{p}<0 \cdot 01$

appearance self ratings. This consistent association was preserved after controlling for IQ, indicating that the mediating effect of intelligence is only partial.

Discrepancy findings for physical appearance were significantly associated with the Pultibeced measure. The pattern of correlations suggests that this association is largely accounted for by high competence ratings as there is no diminution of importance ratings. Where discrepancy of academic self ratings showed an association with severity it was in the reversed direction with the less disabled rating themselves relatively highly.

\section{INFLUENCE OF INDIVIDUAL ASPECTS OF} DISABILITY ON DOMAINS OF SELF ESTEEM

Table 2 demonstrates that global self worth and self rated competence relating to physical appearance show the most consistent correlation with severity. These variables were therefore analysed for associations between specific aspects of functional impairment and these measures (table 3). Small cell numbers limited the possible analyses of the findings and some functional levels were grouped.

In each case, evidence of significant association between severity and self concept was in the direction of increased self worth in the more disabled. High levels of global self worth and physical appearance competence ratings are seen among those young people with higher lesion levels, more restricted mobility, poorer upper limb function, and less functional independence as judged by dressing skills. Surprisingly there was no apparent correlation between the self esteem measures and continence.

THE EFFECTS OF IQ ON SELF CONCEPT AND GLOBAL SELF WORTH

The correlations between IQ and domains of self concept with and without control for severity are shown in table 4 . There is a marginal association whereby the lower the IQ the higher the self worth. This diminishes to total insignificance once severity of disability is controlled. However, once we look at the details of these relationships following Harter's conceptual model, various aspects of process become clear. There is a relationship whereby the lower the intelligence the larger the discrepancy score for physical appearance $(r=-0.423, \mathrm{p}<0.01)$, and this remains once severity of disability is partialled out. As was the case for severity, this association between IQ and physical appearance discrepancy comes from lower IQ individuals having a higher evaluation of their own physical appearance rather than a lowering of its perceived importance to them.

Table 4 also demonstrates the positive associations whereby higher IQ individuals see themselves to be more competent in general academic and general intellectual domains.

\section{SELF ESTEEM AND THE PRESENCE OF}

HYDROCEPHALUS

Specific effects of hydrocephalus were sought on the psychological findings. In spite of the impact of hydrocephalus on IQ there was no evident effect on global self worth. No pattern emerged from analysis of domains of self concept.

Table 3 Means of global self worth and competence ratings for physical appearance as a function of physical status. Parameters with significant correlations only; functional categories grouped for smaller numbers

\begin{tabular}{|c|c|c|c|}
\hline & $\begin{array}{l}\text { Global } \\
\text { self } \\
\text { worth }\end{array}$ & $\begin{array}{l}\text { Physical } \\
\text { appearance } \\
\text { (competence) }\end{array}$ & No \\
\hline \multicolumn{4}{|l|}{ Pultibeced measures } \\
\hline Physical capacity: & & * & \\
\hline Good/exceptional & $2 \cdot 93$ & $2 \cdot 42$ & 24 \\
\hline Low to average & $2 \cdot 77$ & $2 \cdot 43$ & 23 \\
\hline Poor & $3 \cdot 14$ & 3.05 & 23 \\
\hline Upper limbs (arms): & $\star \star$ & $\star \star$ & \\
\hline Normal & $2 \cdot 77$ & $2 \cdot 42$ & 49 \\
\hline Loss of skill & $3 \cdot 35$ & $3 \cdot 12$ & 21 \\
\hline Upper limbs (hands): & $\star$ & $\star \star$ & \\
\hline Normal & $2 \cdot 73$ & $2 \cdot 32$ & 36 \\
\hline Loss of skill & $3 \cdot 18$ & $2 \cdot 95$ & 34 \\
\hline \multicolumn{4}{|l|}{ Locomotion: } \\
\hline Normal/slight difficulty & $2 \cdot 77$ & $2 \cdot 33$ & 19 \\
\hline Moderate difficulty & $2 \cdot 79$ & $2 \cdot 20$ & 15 \\
\hline Severe difficulty & $3 \cdot 11$ & $2 \cdot 96$ & 36 \\
\hline \multicolumn{4}{|l|}{ Toileting: } \\
\hline Normal/nocturnal enuresis & $2 \cdot 69$ & $2 \cdot 33$ & 14 \\
\hline Continent with aid & 3.08 & $2 \cdot 75$ & 34 \\
\hline Incontinent & $2 \cdot 90$ & $2 \cdot 62$ & 22 \\
\hline \multicolumn{4}{|l|}{ Behaviour: } \\
\hline Normal & $2 \cdot 90$ & $2 \cdot 45$ & 41 \\
\hline Behaviour problems & 3.01 & $2 \cdot 88$ & 29 \\
\hline Dressing: & 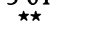 & $\star \star \star \Delta$ & \\
\hline Normal & $2 \cdot 71$ & $2 \cdot 31$ & 36 \\
\hline Requires help & $3 \cdot 19$ & $2 \cdot 96$ & 34 \\
\hline \multicolumn{4}{|l|}{ Disability severity score } \\
\hline Lesion level: & $\star \star$ & $\star \star$ & \\
\hline Sacral & $2 \cdot 64$ & $2 \cdot 16$ & 11 \\
\hline Lumbar & $2 \cdot 79$ & $2 \cdot 42$ & 32 \\
\hline Thoracic & $3 \cdot 32$ & 3.09 & 33 \\
\hline \multicolumn{4}{|l|}{ Shunt operations: } \\
\hline None & $2 \cdot 99$ & $2 \cdot 56$ & \\
\hline 1 & $2 \cdot 97$ & $2 \cdot 50$ & 12 \\
\hline$\geqslant 2$ & $2 \cdot 97$ & $2 \cdot 73$ & 44 \\
\hline Ambulation: & $\star$ & $\star$ & \\
\hline No acids & $2 \cdot 64$ & $2 \cdot 21$ & \\
\hline Braces & $2 \cdot 94$ & $2 \cdot 60$ & 36 \\
\hline Wheelchair & $3 \cdot 26$ & 3.03 & 25 \\
\hline \multicolumn{4}{|l|}{ Bladder function: } \\
\hline Continent & $2 \cdot 78$ & $2 \cdot 49$ & 16 \\
\hline Catheterisation & $2 \cdot 96$ & $2 \cdot 61$ & 48 \\
\hline Collection device & $3 \cdot 25$ & $2 \cdot 92$ & 15 \\
\hline
\end{tabular}

Contrast significant on one way analysis of variance: ${ }^{\star} p<0.05$; ${ }_{\star \star} \mathrm{p}<0 \cdot 01$. 
Table 4 Correlations of $I Q$ with competence ratings, importance ratings, and discrepancy scores. Controlled for Pultibeced and disability severity scores

\begin{tabular}{|c|c|c|c|}
\hline Domain & $\begin{array}{l}\text { Correlation } \\
\text { coefficient } \\
(n=79)\end{array}$ & $\begin{array}{l}\text { Correlations controlled } \\
\text { for Pultibeced } \\
(n)\end{array}$ & $\begin{array}{l}\text { Correlations controlled } \\
\text { for disability severity score } \\
(n)\end{array}$ \\
\hline Global self worth & $-0 \cdot 21$ & $-0.05(67)$ & $-0 \cdot 14(72)$ \\
\hline \multicolumn{4}{|l|}{ Competence: } \\
\hline General intellectual ability & $0 \cdot 19$ & $0.26(67)^{\star}$ & $0 \cdot 20(72)^{\star}$ \\
\hline General academic ability & $0 \cdot 38^{\star \star}$ & $0.32(67)^{\star \star}$ & $0.34(72)^{\star \star}$ \\
\hline Social acceptance & 0.09 & $0.08(67)$ & $0.09(72)$ \\
\hline Athletics & 0.04 & $0 \cdot 13(67)$ & $0 \cdot 10(72)$ \\
\hline Behaviour & $-0 \cdot 17$ & $-0 \cdot 10(67)$ & $-0.14(72)$ \\
\hline Physical appearance & $-0 \cdot 26^{\star}$ & $-0.03(67)$ & $-0.20(72)^{\star}$ \\
\hline \multicolumn{4}{|l|}{ Importance: } \\
\hline General intellectual ability & 0.03 & $0.02(62)$ & $0.04(67)$ \\
\hline General academic ability & -0.09 & $-0.11(63)$ & $-0.09(68)$ \\
\hline Social acceptance & 0.07 & $0 \cdot 14(62)$ & $0 \cdot 16(67)$ \\
\hline Athletics & 0.03 & $0.14(62)$ & $0.04(67)$ \\
\hline Behaviour & -0.02 & $0.03(62)$ & $0.03(67)$ \\
\hline Physical appearance & -0.04 & $-0 \cdot 11(63)$ & $-0.00(68)$ \\
\hline \multicolumn{4}{|l|}{ Discrepancy scores: } \\
\hline General intellectual ability & $0 \cdot 39^{\star \star}$ & $0.37(40)^{\star \star}$ & $0.34(45)^{\star \star}$ \\
\hline General academic ability & $0 \cdot 45^{\star \star}$ & $0.33(56)^{\star \star}$ & $0.40(61)^{\star \star}$ \\
\hline Social acceptance & $0 \cdot 12$ & $0.06(38)$ & $-0 \cdot 12(41)$ \\
\hline Athletics & $0 \cdot 15$ & $0 \cdot 17(20)$ & $0 \cdot 11(22)$ \\
\hline Behaviour & -0.05 & $-0.09(54)$ & $-0.06(57)$ \\
\hline Physical appearance & $-0 \cdot 42^{\star \star}$ & $-0.26(44)^{\star}$ & $-0.41(47)^{\star \star}$ \\
\hline
\end{tabular}

Significance: ${ }^{\star} \mathrm{p}<0.05 ;{ }^{\star \star} \mathrm{p}<0.01$. would appear to have a protective effect on global self worth. However, even when the effect of IQ is controlled for, the more disabled individuals still have greater self esteem in terms of global self worth and physical appearance. Thus low IQ has an additive, independent, protective effect whereby the lower the IQ, the greater the self rating of physical appearance and the greater the global self worth.

It is evident from the scattergrams (figure) that some young people with lesser degrees of disability show low self worth. Evidently some young people, superficially less in need of counselling and support, are at particular risk. Therefore, directing resources in relationship to physical severity may be misplaced. Moreover many of the mildly disabled individuals will be attending mainstream schools where the particular problems of spina bifida may be less well recognised.

In looking for evidence of the impact of specific aspects of disability, the findings of diminished self esteem with more normal functional ability is repeated. The most severely disabled individuals with high spinal lesions, poor mobility, and evidence of diminished upper limb function show higher self esteem in their physical appearance and global self worth.

Mobility $^{11}$ and urinary continence ${ }^{1711}$ might be expected to have a major negative impact on self esteem, though Wallander et al found no relationship between continence and psychosocial adjustment. ${ }^{5}$ Our findings fail to demonstrate an association.

The effect of hydrocephalus on intellect has been described elsewhere. ${ }^{17}$ Given the evidence from the severely disabled group it might have been expected to affect self esteem in the present sample as IQ was significantly lower in those with hydrocephalus than without. Yet there was no apparent relationship between levels of global self worth and the presence or absence of hydrocephalus as judged by their history of valve insertion.

Varni and Wallander suggested that parameters of physical disorder are major risk factors in the differential adjustment of handicapped children and are associated with greater psychosocial stress. ${ }^{18}$ Though we find relationships between physical parameters and self esteem, the severity of disability is a poor indicator of the degree of impact which disability has on young people with spina bifida. The relative lack of evidence of association between specific parameters of disability and self esteem would suggest that it is psychosocial and other factors compounded by the total impact of the disability which modifies these aspects of self concept. Bleck has emphasised the importance of family, social, and cultural considerations in the success, or otherwise, of rehabilitation programs. ${ }^{19}$

Medical, social, and educational interventions to promote the health, developmental progress, and independence of young people with physical disability may appear to be hampered by a failure to align the process with the young person's own expectations and worse in those with milder disorder. ${ }^{9}$ In our study group this is in part an effect of the high self esteem of the most disabled, who have significantly lower IQs than the rest of the group. For the most disabled, a lower IQ 
attitudes. Though the more severely disabled person with spina bifida may have more clearly definable problems, the mildly affected individual may well be more vulnerable and in greater need of appropriately structured support.

We gratefully acknowledge the support of the Association for Spina Bifida and Hydrocephalus in funding this project and the considerable commitment of the young people themselves.

Medical assessments were carried out by $R$ Blackmore, $V$ Klimach, R Pugh, G Clements, and P Minchom. Research assistants V Lawson, C Clerkin, A Llewelyn, and T Gilroy provided invaluable support.

1 Anderson EM, Clarke L. Disability in adolescence. London: Methuen, 1982.

2 Arnold P, Chapman M. Self-esteem, aspirations and expectations of adolescents with physical disability. Dev Med Child Neurol 1992; 34: 97-102.

3 Campbell MM, Hayden PW, Davenport SLH. Psychological adjustment of adolescents with myelodysplasia. fournal of adjustment of adolescents with myelodys

4 Spaulding BR, Morgan SB. Spina bifida children and their parents: a population prone to family dysfunction? parents: a population prone to

5 Wallander JL, Feldman WS, Varni JW. Physical status and psychosocial adjustment in children with spina bifida. $\mathfrak{f}$ Pediatr Psychol 1989; 14: 89-102.

6 Appleton PL, Minchom PE, Ellis NC, Elliot CE, Böll V, Jones $P$. The self-concept of young people with spina bifida: a population-based study. Dev Med Child Neurol 1994; 36: 198-215.

7 McAndrew I. Adolescents and young people with spina bifida. Dev Med Child Neurol 1979; 21: 619-29.
8 Tew B, Laurence KM. Possible personality problems among ten year old spina bifida children Child Care Health Dev 1985; 11: 375-90.

9 McAnarney ER, Pless IB, Satterwhite B, Friedman SB. Psychological problems of children with chronic juvenile arthritis. Pediatrics 1974; 53: 525-8.

10 Lindon RI. The Pultibeced system for the medical assessment of physically handicapped children. Dev Med Child ment of physically handic

11 Thomas AP, Bax MCO, Smyth DPL. The health and social needs of young adults with physical disabilities. Oxford:

12 Renick MJ, Harter S. Manual for the self-perception profile for learning disabled students. University of Denver: University of Denver Press, 1988

13 Harter S. Processes underlying the construction, maintenance and enhancement of the self-concept in children. In: Suls J, Greenwald AG, eds. Psychological perspectives on the self. Volume 3. London: Erlbaum, 1986.

14 Wechsler D. Manual for the Wechsler intelligence scale for children - revised New York: Psychological Corporation (Anglicised version: Windsor: NFER Publishing Company, 1974)

15 Wechsler D A British supplement to the manual of the Wechsler adult intelligence scale - revised. New York: Psychological

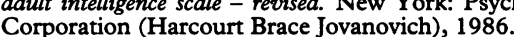

16 Stein RK, Perrin EC, Pless IB, et al. Severity of illness: concepts and measurements. Lancet 1987; ii: 1506-9.

17 Tew $B$. Taurence KM. The ability and attainments of spina bifida patients born in South Wales between 1956-1962. Dev Med Child Neurol 1972; 14 (suppl 27): 124-31.

18 Varni JW, Wallander JL. Pediatric chronic disabilities: hemophilia and spina bifida as examples. In: Routh DK, ed. Handbook of pediatric psychology. New York: Guilford, 1988

19 Bleck EE. Factors affecting independence of the physically disabled. Dev Med Child Neurol 1990; 32: 189-90. 